\title{
The role of peer review in identity development for engineering education researchers
}

\begin{abstract}
Peer review has been the focus of an ongoing study at a series of recent annual conferences of the Australasian Association for Engineering Education (AAEE). A further development of this study has been to explore the perspective/s of the authors of these conference papers and the impact that peer review can have on their development as researchers. This paper uses the identity-trajectory framework to illustrate relationships between peer review and academic identity construction for engineering education authors in the AAEE community.
\end{abstract}

Participants' responses illustrate how various aspects of responding to reviews, and writing reviews for other authors, contribute to the development of the networking and intellectual strands of their academic identity as engineering education researchers. We suggest that members of the global engineering education community should also be mindful of how they write their peer reviews of conference papers so that they constructively contribute to their peers' successful transition into this different research paradigm.

Keywords: peer review, academic identity, identity-trajectory, engineering education researchers, conference papers.

\section{Introduction}

Peer review has been the focus of an ongoing study at the 2010, 2011 and 2012 conferences of the Australasian Association for Engineering Education (AAEE) (Willey et al 2011, Jolly et al 2011, Gardner et al 2012, Jolly et al 2012). A further development of this study has been to explore the perspective/s of the authors of these conference papers and the potential of peer review to support their development as researchers. This is particularly relevant to our community as engineering education research is still emerging as a recognised research area in Australian universities (King, 2008, Kavanagh et al 2012), which is similar to the situation in other parts of the world (Borrego \& Streveler 2014). Researchers such as Williams and colleagues from Europe 
(Williams et al 2014), and Jesiek, Borrego and Beddoes (Jesiek 2009, Borrego 2007 and Beddoes 2011) from the USA have also acknowledged the need to investigate how engineering academics navigate their way into and through the emergent and interdisciplinary field of engineering education research.

Beddoes $(2011,8)$ suggests that one of the results of the emergent nature of engineering education research is that many 'leaders, such as journal editors, are longtime administrators and reformers, but not educational or social science researchers'. This has implications for both the creation and interpretation of review criteria and hence influences what is published and what isn't. Another complicating issue is that most scholars who identify with this emerging field are engineering academics (Borrego and Bernhard 2011). This is an issue because these academics may hold research qualifications and expertise in their own typical engineering field but are faced with developing new perspectives and expertise when moving into educationally related research (Beddoes 2012).

As a result of engineering education research being both emerging and interdisciplinary there is a wide variety of views as to what quality research looks like (Borrego and Bernhard 2011). The implication for authors is that '...reviewers, and audiences, have significantly different knowledge backgrounds. Thus, authors are caught between fields and held accountable to reviewers from different fields and should expect divergent opinions over what is appropriate and accessible' (Beddoes 2011, 25).

Although peer review is required to meet government and institutional requirements for papers to be acknowledged as a research publication, we argue that our engineering education community needs to do more with the peer review process than focusing on gatekeeping and compliance. Feedback in peer review should be aimed at 
assisting authors to develop the standards and norms of the interdisciplinary field and develop researchers' judgement by for example, challenging them to reflect on their perspective, data collection, and interpretation of findings. Similar arguments have been developed in relation to peer review in the domain of science education research (Eisenhart 2002; Roth 2002, Tobin 2002).

For engineering academics, along with our 'engineering disciplinary norms and expectations of what quality research is '(Beddoes 2012,3) when we participate in engineering education research we also bring with us our engineering identities. The importance of our identity in becoming an engineering education researcher is highlighted by Wenger $(1998,160)$, who says that it:

...demands more than just learning the rules of what to do when. It requires the construction of an identity that can include these different meanings and forms of participation... The work of reconciliation [of differing identities] may be the most significant challenge faced by learners who move from one community of practice to another... and is an on-going process....

Developing an academic identity as an engineering education researcher is a multi-faceted, complex and sometimes lengthy process. Swann, Johnson and Bosson (2009) report on the importance of a supportive community in identity formation. Our research looks at how the peer review of conference papers supports researcher identity development within the AAEE community. This paper examines the relationships between the peer review process, both as author and reviewer, and academic identity construction, and suggests implications of this development for the wider engineering education research community.

\section{Background}

Part of the difficulty engineering academics have with becoming the interdisciplinary 
researchers they need to be is that social research is so different to typical engineering research. Alise (2007) showed that there are differences between academic disciplines with regard to preferred research methods with engineering in the disciplinary classification more likely to use quantitative methods and education in the classification more likely to publish research using qualitative and mixed methods. The dominance of quantitative research perspectives and methods has also been noted by Beddoes (2011, 8): 'Despite being an interdisciplinary research area...positivist contributions from fields like psychology are ...more readily accepted without great effort on the part of authors than are critical qualitative approaches...'.

This preference for quantitative research has been attributed to our formal training as engineers which influences expectations and norms for engineering education publications where generally, quantitative and positivist research is dominant (Borrego 2007; Koro-Ljungberg and Douglas 2008; Borrego, Douglas, and Amelink 2009; Douglas, Koro-Ljungberg, and Borrego 2010; Borrego and Bernhard 2011). However, although we may start from a positivistic, quantitative perspective, there is evidence that engineers can learn to incorporate methods from other research traditions: 'Research on primarily U.S. engineering education researchers indicates that they are more comfortable with quantitative research approaches, but are open to qualitative methods when faced with the complexity of studying human beings in classrooms and similar settings...' (Borrego and Bernhard 2011, 23).

Brew $(2001,2006)$ reports on the different ways that academics conceptualise their research and supports the idea that the way academics think about their research is strongly linked to their identity. Other researchers confirm this link between research, writing about research and academic identity: '...research has often been seen as central to academic identities...' (Taylor 2008, 39), the role of researcher is '...key to identity, 
learning and belonging for most academics' (McAlpine, Jazvac-Martek, and Gonsalves $2008,122)$, and for academics writing is '...the key site of contemporary scholarly practice and the performance of scholarly identity...' (Barnacle and Mewburn 2010, 434).

Disciplinary identity is usually constructed through the socialisation processes integrated in completing a PhD in the field of interest. Thompson $(2003,428)$ suggested that 'through interactions with faculty members graduate students are encouraged, reinforced, and rewarded for their display of attributes salient to the academic discipline, and thus academic environment'( p.428). So postgraduate and, to a lesser extent, undergraduate engineering education acts to socialise participants to the context of engineering research which is different to the context of educational research. For engineering academics wanting to change their practice to engineering education research, not only do they have to negotiate the differences inherent in a different type of discipline, in most countries they usually don't have the socialisation process of being a graduate student to become familiar with them. This process is, instead, undertaken through engagement with the engineering education research community.

\subsection{Identity-trajectory}

McAlpine and various colleagues (McAlpine, Amundsen and Jazvac-Martek 2010; McAlpine and Lucas 2011; McAlpine and Amundsen 2011; McAlpine and Turner 2012; McAlpine, Amundsen \& Turner 2013a, b) have proposed a theoretical framework to describe the development of academic identity. This identity-trajectory framework consists of three intertwined strands: intellectual, networking, and institutional, which interact asynchronously over time as modelled in Figure 1. 


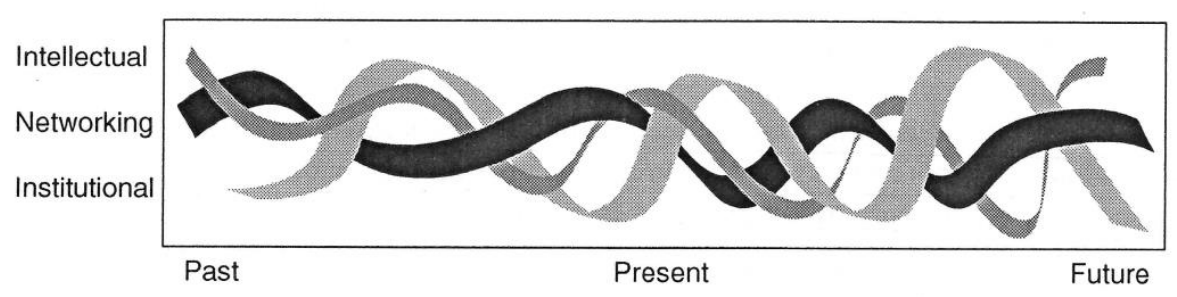

Figure 1. The interweaving of strands of academic identity. (McAlpine and Amundsen 2011, 178).

The intellectual strand represents 'contributions to one's disciplinary specialism or field.

The intellectual strand leaves a trail of artefacts, e.g. publications, citations, papers, course/curriculum design' (McAlpine and Amundsen 2011, 179) and, we suggest, reviews would also be an artefact of this strand.

The networking strand encompasses the academic community beyond the participant's university and includes both an 'interpersonal' and 'intertextual' element. The intertextual element of networking for our participants includes the AAEE community and reviewers as well as the authors of the literature they read and cite. It represents the range of
...local, national, and international networks one has been and is connected to, and...includes (a) research and publication collaborations with others; (b) cross- institutional course/curriculum design; (c) work with professionals...and (d) membership of disciplinary organizations [such as AAEE] and on journal boards." (McAlpine and Amundsen 2011, 179).

The intellectual and networking strands strongly interact with each other with the networking strand 'establishing the intellectual location for one's contributions' (McAlpine \& Amundsen, 2011, 180) and so are largely focussed beyond the individual institution where an academic may be employed. 
However, the framework also includes an institutional strand which represents the interactions of the academic in their workplace. McAlpine and Amundsen (2011, 180) found that institutions can 'support or constrain an individual's networking and intellectual strands'. In our context institutional support of the networking and intellectual strands would be by, for example, providing funding to attend the annual AAEE conference.

Of particular relevance to our research on peer review of conference papers is the notion of the 'intertextual network' which facilitates learning about the discipline area:

Learning through reading involved understanding how scholars in the field communicate through varied genres, e.g. papers, manuscript reviews and funding proposals. Learning the discourse was essential (e.g. how claims are made or the positioning of the researcher/author), but also how textual practices are tied to actual research practices (e.g. what is an appropriate question in a field, what is considered appropriate or essential evidence)... Learning to read-understand in the chosen field is necessary to interacting within the field (McAlpine 2012, 356).

Beddoes $(2012,8)$ also illustrates that reviewers play a part in an author's intertextual network:

... numerous individuals are involved in bringing an article to its published version... articles are often the result of multiple and competing deliberations and negotiations. They contain knowledge and opinions not only of the authors, but also of reviewers and editors.

The appeal of the identity-trajectory concept is that it was developed in an academic context so specifically relates to academic identity development, ie the strands relate to dominant aspects of the academic context. The AAEE community contribute to each others' intertextual network strand of academic identity through the peer review process. In this paper we discuss the direct interaction that the intertextual networking 
process of peer review of a conference paper had with the intellectual strand of the participants' identity development, and the more indirect interaction with the institutional strand.

\section{Our Study}

Our research approach is interpretive using the identity-trajectory concept as a framework or a 'lens' through which to view the data. The framework is used to 'frame' that is to direct the analysis in interpreting the research participants' meanings.

This study focuses on engineering academics with engineering qualifications, who are also 'active' members of AAEE. In this project we are defining engineering academics as 'active' members of AAEE if they authored a paper for the 2012 AAEE conference and at least one of the three previous years' AAEE conferences. The author list from these conferences (available in the proceedings) was used to identify potential participants and these thirty-eight eligible academics were invited to participate in the research project. Nineteen of these authors accepted the invitation. After securing ethics approval from our own institution we interviewed academics from a range of institution types, and with a mixture of levels of experience as educational researchers.

Participants were classified according to what type of university they work for (Group of Eight (Go8), Australian Technology Network (ATN), regional, or metropolitan unaligned as described in Table 1 - for variation in the institutional strand); and their level of expertise in engineering education research (emerging, intermediate, established - for variation in the intellectual and networking strands).

A participant's level of expertise as an engineering education researcher was determined by the number of specific types of publications they had written in the last four years (conference papers, journal papers, book chapters) along with other indicators of research activity such as being the project leader of a grant where the 
funding is provided through a nationally competitive process, whether they are

supervising research students working on educationally related topics, and whether they

were currently serving in an editorial role for an educationally related journal. Using

this system, participants fell into three broad groups: emerging, intermediate, and

established researchers.

Table 1. Participant categorisation by expertise and university.

\begin{tabular}{|c|c|c|c|}
\hline $\begin{array}{c}\text { No. of } \\
\text { participants }\end{array}$ & $\begin{array}{l}\text { Level of } \\
\text { expertise }\end{array}$ & Type of university & Description \\
\hline 4 & emerging & \multirow{3}{*}{ Group of Eight [Go8] } & \multirow{3}{*}{$\begin{array}{l}\text { The 'Group of Eight' } \\
\text { (http://www.go8.edu.au/home) is a coalition of } \\
\text { eight research-intensive universities located in } \\
\text { state capital cities, which tend to be the oldest } \\
\text { universities in Australia. }\end{array}$} \\
\hline 1 & intermediate & & \\
\hline 1 & established & & \\
\hline 1 & intermediate & \multirow[b]{2}{*}{$\begin{array}{c}\text { Australian Technology Network } \\
\text { [ATN] }\end{array}$} & \multirow{2}{*}{$\begin{array}{l}\text { The ATN is an alliance of five universities, } \\
\text { each located in the capital city of a mainland } \\
\text { state of Australia. These universities badge } \\
\text { themselves as practice-based and their research } \\
\text { is focussed on the needs of industry and the } \\
\text { community. }\end{array}$} \\
\hline 2 & established & & \\
\hline 2 & emerging & \multirow{3}{*}{ Regional } & \multirow{3}{*}{$\begin{array}{l}\text { Regional universities are those with their main } \\
\text { campus in a regional city or town rather than a } \\
\text { state capital city. As well as on-campus } \\
\text { students, these universities are characterised by } \\
\text { significant numbers of external/distance } \\
\text { students. }\end{array}$} \\
\hline 1 & intermediate & & \\
\hline 2 & established & & \\
\hline 3 & emerging & \multirow{3}{*}{ Metropolitan unaligned } & \multirow{3}{*}{$\begin{array}{l}\text { The metropolitan unaligned universities are } \\
\text { those based in a state capital city, but not } \\
\text { included in the Go8 or the ATN. }\end{array}$} \\
\hline 1 & intermediate & & \\
\hline 1 & established & & \\
\hline
\end{tabular}

A document analysis was undertaken which compared each participant's draft paper

submitted for review for the 2012 AAEE conference, to the final version of their paper, along with the two reviews of that paper. This document analysis provided background information for the semi-structured interview of each participant. Each interview took approximately an hour and occurred in the timeframe between three weeks and five months after the deadline for submission of the final version of their paper to the 2012 conference. During the interview participants were asked to re-read the reviews they 
received on their paper, comment on how helpful they had found these reviews in preparing the final version of their paper, and explain any changes they had made between the draft and final versions. This generated discussion about the reviews themselves and about the changes the participants had actually made to their papers that were prompted by review comments, or independent of the review comments. It also generated discussion more broadly about their educational research, and about how they write about their research.

The interview context was selected as a means of engaging in a dialogue with appropriate engineering academics about their research and hence generating data which could be analysed for aspects of academic identity. Taylor (2008) specifically mentions interview transcripts as a source of identity discourse:

Interview transcripts and oral histories provide contexts within which identities are rehearsed ... [and] remembering and sharing aspects of personal experience and perspective are themselves creative, rather than objective acts. (p. 29)

Lea and Stierer $(2009,2011)$ explored academic identity through interviews with academics about various texts they had produced in the course of their everyday academic practices. Other identity researchers, for example, McLean and Pasupathi (2012) and Taylor (2008), argue that in narrating both everyday and important events identity is developed and sustained. In line with these research methods, this study is focused on engineering academics identifying as engineering education researchers, and it combines the approach of Stierer $(2009,2011)$ by focusing on an example of text produced by each participant with the approach of McLean and Pasupathi (2012) and Taylor (2008) in exploring an event in relation to that text. The texts examined and discussed were specifically produced for that research domain, namely an AAEE conference, and the contextual event is receiving reviews on a conference paper. 
Transcripts were created from audio recordings of the interviews, which were then manually coded in NVivo 10 for a priori themes relating to identity-trajectory strands (intellectual, networking and institutional). For example, the intellectual strand is referenced in participants' comments relating to research perspectives, methods, data collection, analysis and tools. Comments relating to interactions with other people about research were coded as demonstrating that participant's interpersonal networking strand while comments relating to publications were coded as illustrations of their intertextual networking strand. When participants referred to how some aspect of institutional operation impacted on their ability to undertake engineering education research, this was categorised under their institutional strand. This process involved repeated reading of the transcripts and the descriptions of the academic identity strands.

Quotes from participants used in the following sections indicate their level of expertise and the type of university at which they are employed.

\section{Findings and discussion}

Responses from our participants gave us confidence that our researcher classification system aligned with their perceptions as they self-identified as being at a particular level of expertise:

Being a novice researcher... [emerging, regional];

So I'm in the midpoint of my transition from one to the other. Not generating too many new ideas in the technical research area anymore [intermediate, ATN].

Studying the interview transcripts we were able to find many instances of how the peer review process had impacted on the author's intellectual strand, as well as whether and how their institution supports their identity construction as a researcher in the engineering education field. Participants' explanations of their responses to 
peer review of their conference paper illustrate aspects of their intellectual, networking and institutional strands of identity (Gardner and Willey, 2013). The discussion below focuses on the impact of the peer review process, as part of the intertextual network, on the development of researchers' intellectual and institutional strands.

\subsection{Networking and Intellectual strand interaction}

The intellectual strand is referenced by the comments that many participants make relating to research perspectives, methodologies and tools which is perhaps not surprising in a group transitioning to a different research paradigm. Participants noted that reviewer/s comments made them think differently about a variety of aspects of their paper including how they structured it, the literature and research methods used and how to write about them, as well as their written expression and future research as illustrated below:

Structure:

The reviewers picked up on things, weaknesses that I already knew were in the paper...There was one comment in particular... it changed the way I thought about it... it gave me the, 'Oh now I know what I'm going to do with this paper'. So it certainly did give me the direction that I needed to complete the paper the way I wanted to. [emerging, regional];

So hopefully I've added enough in to deal with what the reviewers, well to deal with any other reader that would have had the same issues that the reviewer would, yeah. So I really did need to add a whole new section based on what the - they said minor changes but in the end it was a significant, well I think it was a significant addition which meant I had to take chunks out as well. [established, regional];

So one of the reviewers gave feedback that really highlighted well you haven't even talked about this bit and actually this is the most important bit and this is the most 
interesting bit. When I read it I thought what the hell are they talking about? But then when I re-read the paper with those comments in my mind I went oh, it's so blatantly obvious. How could anyone understand what I'm talking about here without that information in there... [established, regional];

The literature used:

So this one was more referenced to literature on teaching sustainability and the illustrating concept would be helpful. So I thought I thought I'd done that, dug into the paper, couldn't find it anywhere. Thought yeah, I can see that [intermediate, ATN];

The research methods used and how to write about them:

...one of the comments I got back was, oh, I don't see what the established research methodology is... [emerging, metropolitan unaligned];

There was one comment here [in a review] about the use of the extracts from focus groups. They [reviewer] weren't convinced that that was a way to show results. I'd seen other papers that had done that... it made me think... [emerging, metropolitan unaligned];

...things like where they were saying that there's an unacknowledged possibility of the Hawthorne Effect. Essentially I think their concern was because past students knew they were being researched on, investigated, that they'd perform differently... [emerging, Go8];

...particularly the one I'm looking at here where they were talking about methodology and they just listed a whole heap of things that they were meant to have and I thought that's a fair point, I should have put that in [emerging, metropolitan unaligned];

many of the reviewers comments were focussed around that, and what we were trying to - I think it helped us. What we were trying to measure was almost impossible to measure. So it helped us focus back on - we should have asked a different research question, I think [established, ATN]; 
So I did take up on that suggestion and I went and acquired the student survey written comments and categorised them. So in the next version there's a little table that has - so I went through and categorised them...and it turned out it was kind of interesting ... how the students' comments fell [established, ATN];

\section{Written expression and formatting:}

So I think I got an essence from that from this reviewer 1, where I kind of needed to have a look at it again and while it wasn't a throw the whole lot out and start again, it was certainly critically evaluating each paragraph and wasn't explaining things as well as it needed to be [emerging, regional];

When I get these kinds of reviews I have to sit back and go what have we not conveyed here. We clearly haven't told this story well enough that the reviewer just went off in this direction [established, ATN];

and future research:

Sometimes those things are hard to measure, and I think we all knew that before, but ...we wanted a starting point, and I think we put something down on paper, and the review did help us I think, refine and reflect on where we wanted to go to [established, ATN].

As well as influencing their intellectual strand the review they received prompted them to re-engage with other elements of their intertextual network and think more critically about their sources:

So this one [review] was more referenced to literature... So I ... dug into the paper, couldn't find it anywhere... So that...led me to reading in a more deep way some of the literature that I've already read... I went back to try and find something to quote and I thought this is really a bit thin on pedagogy. So that changed my perception... [intermediate, ATN]. 
Another way that peer reviews extended our participants' intertextual networking strand is through the process of reviewing other authors' conference papers. Several participants commented that they learn from reading the papers they are asked to review, i.e. that reviewing prompts further interweaving of the intellectual and networking strands:

If you're a reviewer, it's also a learning exercise for yourself to go oh this is a really good paper or they've taken an interesting approach or whatever...it's an educational process for the community [established, ATN];

It makes you learn about things that because you now have to read a paper you actually read a bit more... So it is good reviewing because it just makes you read papers that you sometimes just don't get time the read - well, you do have the time if you really made the time but you don't. This just forces you to sit down and read some papers, which is always good [emerging, metropolitan unaligned];

...it's good ... to read other people's work to get an idea of what's out there... Also to get an idea of how other people write... I'll criticise something then realise I've done it myself in my own paper [emerging, Go8];

And they learn more by reading the paper than by just listening to the presentation: ...at a conference presentation if it's the first time you hear about a paper, it just goes over your head. Even if it's a good idea. I write it down, it's still not the same as if I've read it...if I go to their presentation for a paper I've reviewed and I really enjoyed, eventually I meet that person in the lunch queue and I say I really like your paper on ... That will be a really deep connection that happens just because you've reviewed the paper [intermediate, ATN].

This comment also demonstrates how the conference provides an opportunity to transform elements of our intertextual network into part of our interpersonal network ie at the conference we can meet the author/s of papers in our intertextual network in person. 
Especially for a first time reviewer of AAEE papers, reviewing involved a 'paradigm shift' in their thinking about research, and helped them learn about the discourse of the field:

...because I'm outside of my normal field... it was a paradigm shift...in terms of familiarising myself with the field of discourse - engineering education - the whole thing was educational...quite stimulating and valuable...Personally worthwhile... I wouldn't have done it otherwise. I was there to learn about the discourse... As such, getting involved as a reviewer is quite a healthy way to engage yourself in a discourse [emerging, Go8].

An established researcher commented that writing papers and engaging with the review process are connected, which again demonstrates how the intertextual network is intertwined with the intellectual development strand:

...they're all connected, and interconnected, and the fact that we can learn from others - you know I've heard people saying they're not doing reviews or they don't ever do them, and I'm saying well I think you're missing an opportunity to understand how other people have tackled the same issue, and I think we need to open our eyes and be a little bit more adventurous and brave and not be afraid to learn off our peers and give feedback to our peers [established, ATN].

Authors also learned about reviewing by seeing other reviewers' comments (after their review was submitted) as it allowed them to benchmark their thinking:

As a reviewer, after the process is finished, I always do whatever I can to hunt down the comments from the other reviewers on the paper that I reviewed... Anonymously, of course but I still got to see what the other people thought, which was again, very interesting and illuminating for me [emerging, Go8];

There doesn't appear to be a lot of feedback to do a review in this particular process, so without someone coming back and saying well, perhaps you were a bit harsh, or giving you a review on my review then it's whether or not they accept it, that is a very crude way of getting feedback I guess [emerging Go8]. 
Both of these participants are emerging researchers, so this seeking of feedback on their reviews may be a reflection of their lack of confidence in our field, and/or their eagerness to know more.

Perceptions of the quality of the review are also dependent on the expertise of the author i.e. on the sophistication of their intellectual strand. To illustrate this we can see that established researchers think that generally review quality is poor:

...yeah, I think refereeing is ...not all that good these days [established regional];

...sometimes I'll put in a paper and I'll think oh, that's going to get hammered. ... I've run out of time and at least using the reviewing process will give me an opportunity to re-write it. Then it's really sad when it comes back with this is good, accept... you think what? How did that happen? [established, regional];

Some of the reviews that I've seen sometimes I'm really surprised at ... I'm thinking good grief, come on, surely we can take a slightly wider view of the world. We don't have to be so narrow minded. I think there's an element of that [established, Go8];

which we can contrast with statements from emerging and intermediate researchers' perceptions that review quality is improving:

...fairly happy with the reviews I had this year...the reviewers and the reviews that I got have improved... [emerging, regional];

Yeah, the quality of my paper improved more with these reviewer comments than any other conference paper I've ever written [intermediate, ATN];

....and I have to say, I thought the standard of the reviews were probably the best I've seen [emerging, Go8]. 
The peer review process influenced authors' intellectual strand by both receiving reviews and writing them for other authors. This was more evident for emerging than intermediate and established researchers, especially in relation to using and writing about research methods, since emerging researchers typically have further to go in their identity trajectory to become engineering education researchers.

\subsection{Networking and Institutional strand interaction}

Most participants commented that despite producing publications for the university to 'count', engineering education related publications were seen to be second-class and in some places not considered as 'real' research which can be a disincentive for researchers to continue. This perception of the research area as not real research means that authors in that area are also considered by some to be undertaking minor or simple research, not requiring the research competence and skill of so-called technical researchers. Although the authors would argue that these perceptions, particularly within engineering, are often the result of ignorance, for many in particular emerging and intermediate researchers, they have a real impact on identity constructs:

Engineering education has this sort of nebulous sort of - it's almost like a pimple on a pumpkin in many places, even in a place like this.... [emerging, Go8];

We get presentations from our Office of Higher Degrees in Research about what is a reportable... anything that has learning or teaching associated with it, they tend to view fairly cynically when they're trying to determine whether it's real research. If you were testing concrete beams or something, it must be real research. But if you're not they seem to apply almost different standards because they can't quite cope with qualitative and the quantitative difference, I suspect... this seems to be a common thing. Maybe we see it in Engineering Education because we see both sides of the coin. We see the technical researchers and what they do, and say well we're just as rigorous, but we seem to have different standards applied to us... we have to justify our status much more strongly [emerging, regional]. 
An intermediate researcher believes engineering education is regarded as real research at the university where he works, but the interweaving of intellectual and institutional strands is illustrated with his questioning of qualitative research methods at the end of this comment:

It is because of our previous dean. He in fact set up the engineering side, the [engineering education research group]; he supported it greatly. I don't know if it's seen by other researchers as real research. It's seen by other people as a form of research. Most researchers still don't think of it as strong because they don't think that surveys are a scientific approach to do research.... You can interpret the data; that's something else. Data interpretation occurs anywhere. But it's how you obtain the data. By interviews or question/answering. I also question that [intermediate, metropolitan unaligned].

As indicated by this intermediate researcher, some universities actively support engineering education related research with two universities among those represented by our participants having already established a discipline specific research centre. This institutional support has benefits for both the development of authors' networking strand (supporting them to attend the conference) and their intellectual strand (providing resources at their university to support developing expertise):

The school will fund you to go to AAEE conference, at the moment. So they funded four or five of us to go and we wouldn't get funded to go to another conference....[Head of School] funds four to five people every year to go to AAEE, which he doesn't fund any other conferences. [emerging, metropolitan unaligned];

...the previous discipline leader was actively encouraging people to do research into education. Our previous dean was quite keen on it as well... So I guess you do have support because (a) there's people here I can talk to about it and (b) it is actually encouraged by people at senior levels [emerging, metropolitan unaligned]; 
...the only question my university asks in relation to a paper - if you want to have it counted by the bean counters - was it peer reviewed or not? That's the only question they ask... So, in that sense, yeah, the bean counters are counting AAEE papers, for the University. In terms of telling the world this is what our academics have done, yeah, they [count them]. They're peer reviewed... the other reason is that the government actually gives a small amount of funding to the universities for each paper that they publish ... that's what the University cares about [emerging, Go8];

The background to this paper is that I was part of a writing group. We'd meet once a week for 10 weeks or 12 weeks ...So we'd exchange ideas within that group as well; assimilate ideas... it was run by the people in the [faculty] education research group [intermediate, metropolitan unaligned];

We had a presentation internally so it'd gone through a thorough process and we took some of those recommendations on board from the internal reviewers. Some of those internal reviewers are also reviewers for AAEE, for other papers [intermediate, metropolitan unaligned];

...we have a very large engineering and science education research group, ...so most of the other people in the faculty, even if they don't directly do engineering education research, they're at least aware that other people are doing it. That it's...contributing to the research quantum of the university... So yes, engineering and science education is valued, certainly by the faculty and I think by the university, because it brings in papers and stuff [established, metropolitan unaligned].

Hardre et al (2011) and Bailey (1999) report that efficacy is an important factor relevant to faculty productivity. They argue that 'because institutions gain from productive faculty, it follows that institutions will benefit from investing resources to give faculty the tools they need to be efficacious in doing research' (Bailey 1999, 60) such as training in technology tools and methods. They also found that departmental support was consistently and strongly predictive of efficacy for research which is also consistent with Wood's $(1990,60)$ findings that: 
....academic faculty believe in and value academic autonomy... in choice of research topics and scholarly pursuits. The implication of these findings is that administration and policy should provide for and support academic autonomy and choice for faculty. Departmental support was also an important factor in predicating efficacy, which further underscores the implication that faculty members need to see their departments and institutions as supportive of their efforts and development of research skills and tools.

Our study suggests that this is more important for our emerging and intermediate level researchers as they transition into this emerging research domain from a typical engineering academic background. Established researchers have more institutional capital by virtue of the research output they have already demonstrated. As, typically, Associate Professors and Professors they can activate more institutional capital than researchers at the Lecturer or Senior Lecturer level. Regardless of the type of university, we found that, because of the emerging nature of the research domain, this support is often dependent on the attitude of a local leader with strong views on the subject e.g. a Departmental or School Head, or a Dean, and that once this person goes, support for educational research within that unit can go with them.

While McAlpine (2012) suggests that institutions should support the development of their research students' intertextual network with specific pedagogical strategies, Murray $(2013,90)$ calls on universities to explicitly support writing for all academics:

It is not sufficient, therefore, for individuals to engage with writing; institutions must engage with writing too, not only by acknowledging the role of engagement with writing but also by acknowledging the role of writing in academic work. For those with responsibility for developing research capacity, the implication of this study is that they should not assume that new researchers in all disciplines should be left to find their own way to make writing part of their work. 
In the context of engineering education research in Australia we suggest that such institutional resources are unlikely to be forthcoming, except perhaps in the few universities with specific research groups, and a more practicable way to facilitate such development is through the production of conference papers for the AAEE conference. Murray $(2013,87)$ found that academics talk about disengaging with other academic activities in order to write and for many this was difficult but this process was helped by engaging in 'relationships with others who write'. Without institutional engineering education research groups, the AAEE community is important as the space where individuals will find these other academics who write about engineering education.

\subsection{Wider implications}

Our participants quoted earlier in this paper show how various aspects of responding to reviews, and writing reviews for other authors, contribute to the development of the networking and intellectual strands of their academic identity as engineering education researchers. The peer review process is valued by them as it drives writing and even research design and helps learning in our field:

So I think reviewing conference papers is a very important part of mixing the ideas throughout the community... [intermediate, ATN];

...if you don't have a proper review process you just don't write the papers as well. You don't think as much about your own papers, you don't review the literature in such a deep way, you don't construct your argument so well, and so on and so on. ... So, in terms of the profile of engineering education research, I think it's really vital that we do this. This is something that we can do as a community... [intermediate, ATN];

I think as well it's about improving the work that's going on within the community, beyond the actual paper. So if you know that in order to get published in this community, you need to have done this and done this and done this. Then I think 
that that would push more people to finding out how to do that better, before they even get to writing the text...if I have to able to describe the method and the literature that I've drawn from, and state some sort of conclusion that is in some ways saying something to someone else in a different context, then I'm going to think differently about what I do [established, metropolitan].

The intentional use of peer review to contribute to each others' development as researchers also has implications for lifting the profile of the engineering education community:

If we want to get taken seriously as a valid research sector, we as a community need to be responsible for the quality of what we put in... All you need are a couple of really crappy papers in the conference proceedings, and it's enough to undermine... So, I think...if we want to get taken seriously, we have to be our own quality control meter [emerging, Go8];

I think the reviews should be there so that total crap doesn't get published. Because they do become public documents of the society. They're there for people to access and use however they will in the future... [emerging, Go8].

Since the peer review process has implications for the identity development of both individual researchers in the field and for the field overall, reviewers need to demonstrate integrity. It seems ethical, appropriate and responsible to expect and demand reviewers to pay attention to how they write reviews.

While we have concentrated on the members of the AAEE community transitioning from typical engineering research areas into engineering education research, we acknowledge that this community also enjoys the participation of researchers with disciplinary backgrounds other than engineering. What effect our peer review process has on their academic identity is still to be explored. 


\section{Conclusions}

Identity-trajectory has provided a useful theoretical framework in understanding the inter-relationships between the intellectual, networking and institutional aspects of academic identity construction for members of the engineering education community in Australia. For most participants in this study the usual disciplinary socialisation process of completing a $\mathrm{PhD}$ in the field is not practicable and this process is, instead, undertaken through engagement with the engineering education research community. The AAEE community contributes to each others' intertextual network strand of academic identity through the peer review process. This paper demonstrates the potential of peer review to also contribute to the development of an author's intellectual strand, especially for emerging researchers, and we encourage reviewers to be mindful of this potential and write reviews that are more than artefacts of compliance. It has also demonstrated the impact of the institutional environment on this identity development. We argue that these findings can be transferred to international contexts where engineering academics develop their educational research identity through participating in activities of the research community (such as a conference) rather than by undertaking a formal course of study.

\section{Acknowledgements}

We acknowledge those members of the AAEE community who responded so openly to this research.

The research in this study was undertaken after Human Research Ethics approval was granted: UTS HREC 2012-11A.

\section{References}


Alise, M. 2007. "Disciplinary differences in preferred research methods: a comparison of groups in the Biglan classification scheme" unpublished doctoral dissertation. Louisiana State University and Agricultural and Mechanical College, Baton Rouge, LA.

Bailey, J. G. 1999. “Academics' motivation and self-efficacy for teaching and research" Higher Education Research and Development 18 (3): 343-359.

Barnacle, R., and Mewburn, I. 2010. "Learning networks and the journey of 'becoming doctor"' Studies in Higher Education 35(4): 433-444, DOI:

$10.1080 / 03075070903131214$

Beddoes, K. 2011. "Practices of Brokering: Between STS and Feminist Engineering Education Research" unpublished PhD dissertation, Virginia Tech, Department of Science and Technology Studies, Blacksburg, Virginia.

Beddoes, K. 2012. "Using peer reviews to examine micropolitics and disciplinary development of engineering education: a case study". Discourse: Studies in the Cultural Politics of Education, DOI:10.1080/01596306.2012.745735

Borrego, M. 2007.”Conceptual difficulties experienced by engineering faculty becoming engineering education researchers" Journal of Engineering Education 96(2): 91-102.

Borrego, M., Douglas, E. P., and Amelink, C. T. 2009.’Quantitative, qualitative, and mixed research methods in engineering education" Journal of Engineering Education 98(1): 53-66.

Borrego, M. and Bernhard, J. 2011. "The emergence of engineering education research as an internationally connected field of inquiry" Journal of Engineering Education 100 (1): 14-47.

Borrego M. \& Streveler, R. 2014, 'Preparing engineering educators for engineering education research', in A. Johri \& B. Olds (eds), Cambridge handbook of engineering education research, Cambridge Press, New York, pp. 457-475

Brew, A. 2001. "Conceptions of Research: A phenomenographic study" Studies in Higher Education 26 (3): 271-285.

Brew, A. 2006. Research and Teaching: Beyond the Divide. London: Palgrave Macmillan.

Douglas, E.P., Koro-Ljungberg, M., and Borrego, M. 2010.”Challenges and promises of overcoming epistemological and methodological partiality: Advancing 
engineering education through acceptance of diverse ways of knowing" European Journal of Engineering Education 35(3): 247-257.

Eisenhart, M. 2002.'The paradox of peer review: Admitting too much or allowing too little?" Research in Science Education 32 (2): 241-255.

Gardner, A., Willey, K, Jolly, L. \& Tibbits, G. (2012) "Peering at the peer review process for conference submissions", Proceedings of the Frontiers in Education Conference, 3-6th October, Seattle, USA.

Gardner, A., \& Willey, K. (2013) "Exploring the impact of peer review on the development of engineering education researchers", Proceedings of the Annual Conference of the Australasian Association for Engineering Education, December, Gold Coast, Australia.

Hardre, P., Beesley, A., Miller, R. and Pace T. 2011. "Faculty Motivation to do research: across disciplines in research-extensive universities" The Journal of the Professoriate 5 (1): 35-69.

Jesiek, B. K., Newswander, L. \& Borrego, M. 2009, 'Engineering education research: discipline, community, or field?', Journal of Engineering Education, vol. 98, no. 1, pp. 39-52.

Jolly, L., Tibbits, G., Willey, K. \& Gardner, A., (2011) "Conferences, reviews and conversations about improving engineering education", Proceedings of the Research in Engineering Education Symposium, October, Madrid, Spain.

Jolly, L., Willey K., \& Gardner, A. (2012) "Quality in Engineering Education Research: arriving at consensus", Proceedings of the Annual Conference of the Australasian Association for Engineering Education, 3-5 December, Melbourne, Australia.

Kavanagh, L., O’Moore, L., and Jolly, L. 2012. "Mad as hell and not taking it any more?: job satisfaction amongst engineering educators in Australian universities". Paper presented at the annual conference of the Australasian Association for Engineering Education, Melbourne, Australia, 3-5 December.

King, R. 2008. "Addressing the supply and quality of engineering graduates for the new century". A report prepared for the Carrick Institute for Teaching and Learning in Higher Education, Australia.

Koro-Ljungberg, M., and Douglas, E.P. 2008. "State of qualitative research in engineering education: Meta-analysis of JEE Articles, 2005_2006” Journal of Engineering Education 97(2): 163-175. 
Lea, M. R. \& Stierer, B. 2009, 'Lecturers' everyday writing as professional practice in the university as workplace: new insights into academic identities'. Studies in Higher Education, vol. 34, no. 4, pp. 417-428.

Lea, M. R. \& Stierer, B. 2011, 'Changing academic identities in changing academic workplaces: learning from academics' everyday professional writing practices', Teaching in Higher Education, vol. 16, no. 6, pp. 605-616.

McAlpine, L., Jazvac-Martek, M., and Gonsalves, A. 2008. "The question of identity: Negotiating roles and voices in evolving academic systems" in Changing Identities and Voices in Higher Education, R. Barnett \& R. Di Napoli (Eds.), Abingdon: Routledge.

McAlpine, L., Amundsen, C., and Jazvac-Martek, M. 2010. "Living and imagining academic careers" in Becoming an academic: International Perspectives, ed. L. McAlpine and G. Akerlind. London: Palgrave Macmillan.

McAlpine L. and Lucas L. 2011. "Different places, different specialisms: similar questions of doctoral identities under construction" Teaching in Higher Education 16(6): 695-706.

McAlpine, L. and Amundsen, C. 2011. "Making Meaning of diverse Experiences: Constructing an identity through time", in Doctoral Education: Research-based strategies for doctoral students, supervisors and administrators, L. McAlpine \& C. Amundsen (eds). London: Springer.

McAlpine L. and Turner, G. 2012: "Imagined and emerging career patterns: perceptions of doctoral students and research staff" Journal of Further and Higher Education 36(4): 535-548.

McAlpine, L. 2012. "Shining a light on doctoral reading: implications for doctoral identities and pedagogies" Innovations in Education and Teaching International, 49(4): 351-361.

McAlpine, L., Amundsen, C. and Turner, G. 2013a. "Constructing post-PhD careers: negotiating opportunities and personal goals" International Journal for Researcher Development 4 (1): 39-54

McAlpine, L., Amundsen, C. and Turner, G. 2013b. "Identity-trajectory: reframing early career academic experience" British Educational Research Journal, doi: 10.1002/berj.3123 
McLean, K. C. \& Pasupathi, M. 2012, 'Processes of identity development: where I am and how I got there', Identity: An International Journal of Theory and Research, vol. 12 , no. 1 , pp. 8-28.

Murray, R. 2013. “'It's not a hobby': reconceptualizing the place of writing in academic work" Higher Education 66(1): 79-91.

Roth, W. M. 2002. "Editorial power/authorial suffering" Research in Science Education 32 (2): $215-240$.

Swann, W. B., Johnson, R. E., and Bosson J. K. 2009. "Identity formation at work", Research in Organizational Behaviour 29: 81-109.

Taylor, P. 2008. "Being an Academic Today" in Changing Identities in Higher Education: Voicing Perspectives R. Di Napoli \& R Barnett (eds). Abingdon: Routledge.

Thompson, M. 2003. "Disparate academic environments: An emergent framework of socialization" The Qualitative Report, 8(3): 408 - 434.

Tobin, K. 2002. "The multiple faces of peer review in science education” Research in Science Education 32 (2): 135-156.

Wenger, E. 1998. Communities of Practice. New York: Cambridge University Press.

Willey, K. Jolly, L. Tibbits G. \& Gardner, A. (2011) "Investigating research quality and the review process: some suggestions for improvement", Proceedings of the 39th Annual SEFI conference, J Bernardino and J. C. Quadrado (eds), September 2730, Lisbon, Portugal.

Williams, B., Wankat, P., Neto, P. \& Tiago, C. 2014, 'Is engineering education research global? The answer may surprise you', $121^{\text {st }}$ ASEE Annual Conference \& Exposition, 15-18 June, Indianapolis, USA.

Wood, F. 1990. "Factors influencing research performance of university academic staff" Higher Education 19: 81-100. 